OPEN ACCESS

Edited by:

Narasaiah Kolliputi,

University of South Florida,

United States

Reviewed by:

Nisha Dhanushkodi,

University of California, Irvine,

United States

Vidyani Suryadevara,

Rush University, United States

*Correspondence:

Fatemeh Saghafi

f.saghafi@ssu.ac.ir

saghafi.fa@gmail.com

Specialty section:

This article was submitted to

Respiratory Pharmacology,

a section of the journal

Frontiers in Pharmacology

Received: 02 July 2021 Accepted: 12 November 2021

Published: 06 December 2021

Citation:

Alizadeh Z, Sahebnasagh A, Hadadzadegan N, Mohammadi $F$ and Saghafi $F$ (2021) Effects of Donepezil and Medroxyprogesterone Versus Placebo on Weaning in Adult Patients

With Non-Pulmonary Etiologies

Receiving Invasive Mechanical Ventilation: A triple-blind Randomized

Clinical Trial.

Front. Pharmacol. 12:735594. doi: 10.3389/fphar.2021.735594

\section{Effects of Donepezil and} Medroxyprogesterone Versus Placebo on Weaning in Adult Patients With Non-Pulmonary Etiologies Receiving Invasive Mechanical Ventilation: A triple-blind Randomized Clinical Trial

\author{
Zahra Alizadeh ${ }^{1}$, Adeleh Sahebnasagh ${ }^{2}$, Navid Hadadzadegan $^{3}$, Farhad Mohammadi $^{4}$ and \\ Fatemeh Saghafi ${ }^{5 *}$ \\ ${ }^{1}$ Pharmaceutical Sciences Research Center, School of Pharmacy, Shahid Sadoughi University of Medical Sciences and Health \\ Services, Yazd, Iran, ${ }^{2}$ Clinical Research Center, Department of Internal Medicine, School of Medicine, North Khorasan University \\ of Medical Science, Bojnurd, Iran, ${ }^{3}$ Clinical Research Center, Department of Internal Medicine, School of Medicine, North \\ Khorasan University of Medical Science, Bojnurd, Iran, ${ }^{4}$ Department of Pharmaceutics, School of Pharmacy, Shahid Sadoughi \\ University of Medical Sciences and Health Services, Yazd, Iran, ${ }^{5}$ Department of Clinical Pharmacy, School of Pharmacy, Shahid \\ Sadoughi University of Medical Sciences and Health Services, Yazd, Iran
}

Background: Medroxyprogesterone and donepezil could be used as respiratory stimulants in ventilated patients. However, no randomized placebo-controlled trial is available to confirm this approach and compare these drugs. The aim of the current study was to evaluate the effects of donepezil or medroxyprogesterone compared to the placebo in improvement in respiratory status and weaning facilitation in critically ill adult patients receiving mechanical ventilation.

Material and Methods: This randomized, triple-blind trial was conducted on 78 ventilated patients in intensive care units (ICU). Patients who were intubated due to pulmonary disorders were ruled out. Patients were randomized in a 1:1:1 ratio to receive 5 mg donepezil $(n=23)$ or 5 mg medroxyprogesterone $(n=26)$, or placebo $(n=24)$ twice a day until weaning (maximum 10 days). The primary endpoints were weaning duration, and duration of invasive mechanical ventilation. Secondary endpoints included rate of successful weaning, changes in arterial blood gas (ABG) parameters, GCS and sequential organ failure assessment (SOFA) score, hemoglobin (Hgb), ICU-mortality, and duration of ICU stay, were measured before and after the intervention and if successful weaning was recorded.

Results: Of 78 studied patients who were randomized, 59 weaned successfully. 87\% patients in donepezil and $88.5 \%$ patients in medroxyprogesterone groups were successfully weaned compared to $66.7 \%$ patients in the placebo group. However, this difference was not statistically significant $(p$-Value $=0.111)$. Changes in $\mathrm{pH}$, mean duration of intubation, and weaning duration were statistically different in donepezil compared with 
the control group (p-Value < 0.05). No significant difference in ABG, Hgb, GCS and SOFA score, and duration of intubation were seen in the medroxyprogesterone group, but weaning duration was significantly reduced to 1.429 days compared with the control group $(p-$ Value $=0.038)$.

Conclusion: The results of this clinical trial have demonstrated that the administered dose of medroxyprogesterone and donepezil can expedite the weaning process by reducing the weaning duration compared to placebo. Furthermore, the total duration of invasive ventilation was significantly lower in the donepezil group compared to the control group. Future clinical trials with a larger sample size will determine the exact role of medroxyprogesterone and donepezil in mechanically ventilated patients.

Clinical Trial Registration: https://irct.ir/IRCT20190810044500N2 (April 1, 2020).

Keywords: mechanical ventilation, weaning, medroxyprogesterone, donepezil, clinical trial

\section{INTRODUCTION}

Mechanical Ventilation (MV) with positive pressure was first introduced clinically in the 1950s during the polio epidemic (Dries and Perry, 2008). Although positive pressure ventilation is one of the most important medical care interventions nowadays and can be vital in cases with indications, duration of intubation correlates with an increased mortality rate (Dries and Perry, 2008; Peñuelas et al., 2011). Because of the ventilator-associated complications, the weaning process should be initiated as soon as possible (McLean et al., 2006).

About $20-30 \%$ of ventilated patients are considered difficult to wean from invasive MV (Heunks and Van Der Hoeven, 2010). The time spent in the weaning process may necessitate $40 \%$ of the overall duration of MV (Cohen et al., 2019). Difficulty in weaning can be due to reduced central respiratory stimulants, which is often accompanied by the decreased level of consciousness, nervous system damage, and metabolic encephalopathy (Chao and Scheinhorn, 1998).

In spite of insufficient data regarding the efficacy of respiratory stimulants such as caffeine and doxapram (Giguère et al., 2008), researchers are still seeking for new strategies to reduce duration of intubation and treatment costs (Dasta et al., 2005). Available evidence indicates that muscarinic acetylcholine receptors have potent excitatory consequences on medullary respiratory neurons and motoneurones, and are likely to contribute to changes in central hemosensitive drive to the respiratory control system (Yamada and Ichinose, 2018). On one hand the central role of cholinergic mediators in the respiratory system is the basis for its positive effects in neurological disorders related to respiratory control (Abbasi et al., 2015). On the other hand, the parafacial respiratory group plays an important role in the generation of active expiration and recruitment of expiratory abdominal muscles. It is under GABAergic and cholinergic control and is activated in conditions of high metabolic demand (Pisanski and Pagliardini, 2019). Donepezil, a cholinergic drug that reversibly and non-competitively inhibits central acetyl-cholinesterase, has improved cognitive function significantly (Abbasi et al., 2015). As thalamic cholinergic deficit may contribute to obstructive sleep apnea (OSA), donepezil could be a potential modality to improve OSA (Gilman et al., 2003; Moraes et al., 2008; Sukys-Claudino et al., 2012).

Progesterone is a respiratory stimulant improving ventilation function, ventilation capacity, and exercise efficiency in normal individuals and obstructive airways diseases. Progesterone could enhance ventilation, breathing overnight and respiratory gas exchanges (Schoene et al., 1980; Delaunois et al., 1985; Wagenaar et al., 2003; Golparvar et al., 2005; Saaresranta et al., 2005). The lipophilic properties of progesterone allow it to enter the hypothalamic sites that are mediated by estrogen (E2) receptors in the central nerve system (CNS) (Bayliss and Millhorn, 1992). Another proposed mechanism is that progesterone stimulates leptin hormone release, which may increase ventilation (Saaresranta et al., 2002).

The aim of the current study was to evaluate the effects of donepezil or medroxyprogesterone compared to the placebo in improving the respiratory status and weaning facilitation in critically ill adult patients with non-pulmonary etiologies receiving mechanical ventilation for the first time. In addition to weaning duration, and duration of invasive mechanical ventilation as our primary endpoint, we evaluated secondary endpoints, including successful weaning rate from $\mathrm{MV}$, changes in arterial blood gas (ABG) parameters, GCS and sequential organ failure assessment (SOFA) score, hemoglobin (Hgb), ICU-mortality, and duration of intensive care units (ICUs) stay, were measured before and after the intervention and if successful weaning was recorded.

\section{METHODS}

\section{Patients}

This randomized triple-blind placebo-controlled clinical trial was conducted in Rahnemoon tertiary referral hospital affiliated to Shahid Sadoughi University of Medical Sciences, which is the neurological referral center of Yazd city. Recruitment was conducted from December 20, 2019, through July 22, 2020. 
Inclusion criteria were age older than 18 years, MV through the endotracheal tube for at least $24 \mathrm{~h}$ (hrs) prior to study enrollment, oxygen saturation $\left(\mathrm{O}_{2} \mathrm{Sat}\right)$ greater than $90 \%$, Fraction of inspired oxygen $\left(\mathrm{FIO}_{2}\right)$ less than $50 \%$, and positive end-expiratory pressure (PEEP) less than $8 \mathrm{~cm} \mathrm{H}_{2} \mathrm{O}$, Hemodynamic stability during the last $12 \mathrm{~h}$, discontinuation of sedatives or reduction of sedation for the past $48 \mathrm{~h}$, neurologic stability with Ramsay score $\leq 5$, and body temperature between 36 and 38 centigrade degrees $\left({ }^{\circ} \mathrm{C}\right)$.

Exclusion criteria were pregnancy or lactation, known allergy to donepezil or medroxyprogesterone, Alzheimer disease, tracheostomy, hepatic encephalopathy, sever cerebral edema, acute hydrocephalus, myasthenia gravis, acute polyneuropathy, prolonged cardiac arrest with poor neurological prognosis, acute right ventricular failure, history of renal failure, blood urea nitrogen $(\mathrm{BUN})>25 \mathrm{mmol} / \mathrm{L}$, plasma creatinine $>180 \mathrm{mmol} / \mathrm{L}$ or creatinine clearance $<30 \mathrm{ml} / \mathrm{min}$, or more than $25 \%$ increase in creatinine over the last $24 \mathrm{~h}$; contrast injection in the last 6 hours; serum sodium level $>150 \mathrm{mEq} / \mathrm{L}$, serum potassium level $<3.5$ $\mathrm{mEq} / \mathrm{L}$, metabolic alkalosis with arterial $\mathrm{pH}>7.5, \mathrm{GCS}=3$, and concomitant administration of potential respiratory stimulants. Had not taken donepezil or medroxyprogesterone during the previous 14 days (according to the half-lives of drugs). We also excluded patients with known underlying lung disease as the severity of lung disease can influence the duration and success rate of the weaning.

\section{Study Design}

The anesthesiologist, ward nurses, and the data collector were all blinded to the intervention assignments throughout the study. Patients were randomized in a 1:1:1 ratio to one of three groups including medroxyprogesterone $(n=26)$ or donepezil $(n=26)$ or placebo $(n=26)$ based on a random number table. Before attempting to wean patients from $\mathrm{MV}$, the necessary assessment were performed before conducting a spontaneous breathing trial. For intervention groups, medroxyprogesterone and donepezil were administered $10 \mathrm{mg} /$ day ( $5 \mathrm{mg} / \mathrm{BID})$ and patients in the control group received the placebo twice daily until weaning and for a maximum of 10 days. Weaning failure was considered as the need for tracheostomy or intervention for more than 10 days.

\section{Preparation of Placebo Tablets}

For preparation of placebo tablets, the determined amount of lactose, microcrystalline cellulose, and stearic acid was weighted exactly, mixed with a tumbler mixer, and directly compressed with a single punch tablet press machine. The hardness and thickness of placebo tablets were adjusted similar to donepezil and medroxyprogesterone tablets. Placebo was prepared in the Pharmaceutics Laboratory of Shahid Sadoughi School of Pharmacy, Yazd. Donepezil and medroxyprogesterone tablets were purchased from Sami Saz and Iran Hormone pharmaceutical companies, respectively.

\section{Data Gathering}

Demographic information, registry numbers, and dates of reception were recorded in the prepared questionnaire. The following variables including $\mathrm{ABG}\left(\mathrm{PaO}_{2}, \mathrm{PaCO}_{2}, \mathrm{HCO}_{3}, \mathrm{pH}\right.$, and $\mathrm{O}_{2}$ Sat), GCS, Hbg, and SOFA scores were recorded before the intervention, after $24 \mathrm{~h}$, and if successful weaning happened.

\section{Weaning Procedure}

When the patient remains clinically stable, the weaning process starts with assessing the ability of the patient for breath spontaneously. Spontaneous breathing included using continuous positive airway pressure (CPAP), or invasive ventilation with low pressure support, for some cases supplemental oxygen through a T-piece connection applies, If the patient develops signs of poor tolerance, weaning is considered to have failed and mechanical ventilation is reinstituted (Zein et al., 2016).

\section{Randomization}

By applying permuted block randomization, we randomly allocated the eligible patients into one of three arms of the study. For this reason, we used blocks of four. The principal investigator, who was unaware of the interventions, gave one digit number to each prepared formulation from 1 to 78 . The first eligible person was given to number 1 , the second person as number 2, and so on. The anesthesiologist, the ward nurses, and the data collector were all blinded to the intervention assignments throughout the study. In the end, the prepared formulation were decoded and assigned to the proper arm of the study by the main principal.

\section{Sample Size}

The sample size was estimated as 26 per group based on earlier experience and $\mathrm{HCO}_{3}^{-}$standard deviation in donepezil and medroxyprogesterone groups of 0.3 and 7.4 , respectively in order to reach a mean difference (reduction in total clinical score) of 4 with the following specifications and using the sample size eq. $n=\frac{\left(Z_{\left(1-\frac{\alpha}{2}\right)}+Z_{1-\beta}\right)^{2} 2 S^{2}}{\left(\mu_{1}-\mu_{2}\right)^{2}}$, for comparing two means; the estimated sample size was increased to 27 per group to take account of potential attrition $10 \%(\alpha=0.05 ; \beta=0.2)$.

\section{Statistical Analysis}

The quantitative and qualitative variables were reported as mean \pm standard deviation (SD) and number (frequency), respectively. The normality of the data was checked by Kolmogorov-Smirnov test. The distributed quantitative variables were compared between groups by using the independent sample $t$-test and Mann-Whitney, respectively. Moreover, paired $t$-test was used to compare changes of variables at groups over $24 \mathrm{~h}$ and repeated measurement to compare the changes of variables over time. Chi-square and Fisher's exact tests were used to test to compare qualitative variables. Two-way ANOVA and General Liner model were applied to evaluate the simultaneous effects of medications, time and variables changes. All the statistical analysis was conducted by Statistical package for social science (SPSS) software version 23 and two-tailed $p$-values $<0.05$ were considered statistically significant. 


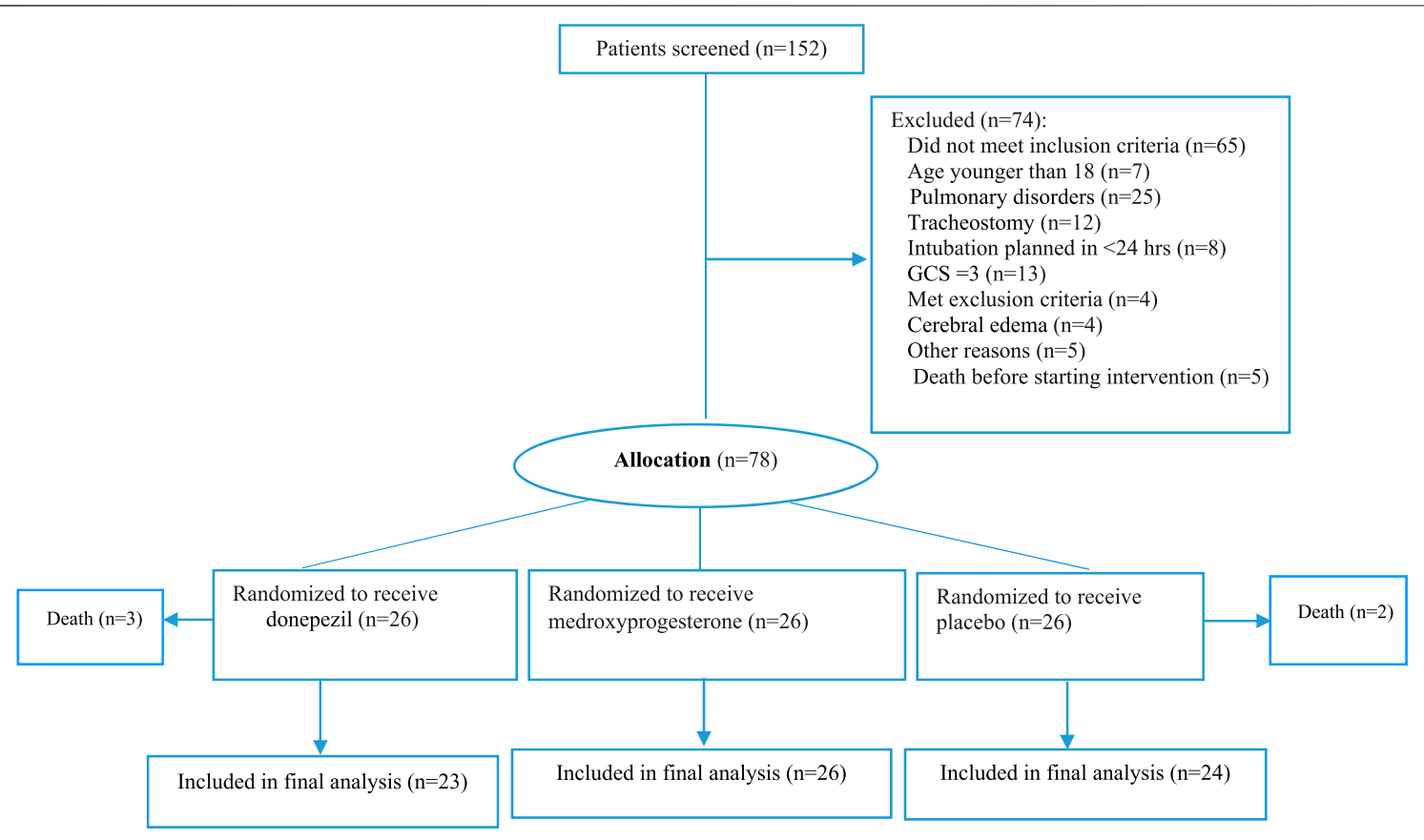

FIGURE 1 | Flowchart of the study.

\section{RESULTS}

In total, 152 patients were screened for eligibility in three neurological ICUs of our hospital. We enrolled 78 intubated patients without primary pulmonary diseases. The mean age of the participants was $41.23 \pm 24.2$ years old. The total intention to treat population were 73 patients who randomly assigned to the following groups: 26 patients each assigned to the control, donepezil, or medroxyprogesterone groups. Five patients were withdrawn from the study subsequently. Eventually, 73 patients completed the study for outcome measurement (Figure 1). Patients in studied groups were balanced in terms of demographic and disease characteristics (Table 1). In order to adjust stroke and head injury covariance analysis was used. By entering these variables into the model, significant difference have been seen between groups $(p$-Value $=0.015)$.

\section{Primary Outcomes}

The mean (SD) of total duration of invasive ventilation was 142.8 (47.4) hrs in the medroxyprogesterone and 124.8 (51.36) hrs in the donepezil groups vs. 176.4 (64.8) hrs in the control group, for a between-group difference of $33.6 \mathrm{~h}$ for medroxyprogesterone group and $51.6 \mathrm{~h}$ for donepezil compared to the control group. As presented in Table 2, the mean total duration of invasive ventilation was significantly lower in the donepezil compared to the control group ( $p$-Value $=0.02)$.

For the medroxyprogesterone, compared to the donepezil group, no significant between-group differences were found for the mean duration of weaning (64.5-83.2-56.4 h, $p$-value $=0.793$ ). The duration of weaning was a mean (SD) of $98.8(46.8)$ hrs in the control group vs. 64.5 (42.96) hrs and 56.4 (35.76) hrs for medroxyprogesterone and donepezil respectively, for a between-group difference of 34 and $42.4 \mathrm{~h}$ in the donepezil and medroxyprogesterone groups, respectively. This value did significantly in the groups $(p$-Value $<0.05)$ (Table 2).

\section{Secondary Outcomes}

From 73 enrolled patients who were randomized in 1:1:1 ratio to one of three groups, $16(66.7 \%)$ patients in control, $23(88.5 \%)$ patients in medroxyprogesterone, and 20 (87\%) patients in the donepezil group experienced successful weaning during the study period. However, the rate of successful weaning were greater in the donepezil and medroxyprogesterone compared to the control group this difference was not statistically significant by ChiSquare test $(p$-Value $=0.111)$.

The comparison between group differences was done using the ANOVA and Tukey HSD test. In successfully weaned patients, the total duration of ICU stay was the mean (SD) of 453.6 (232.8) hrs in the medroxyprogesterone and 352.8 (180) hrs in the donepezil groups vs. 434.4 (170.4) hrs in the control group, for a between-group difference of -19.68 and $79.2 \mathrm{~h}$ for the medroxyprogesterone and donepezil groups respectively. However, this value did not differ significantly between the groups $(p$-Value $=0.245)$. The rate of ICU mortality was not different between groups, as 4 (25\%) patients in control, $5(21.7 \%)$ in medroxyprogesterone, and $3(15 \%)$ patients in the donepezil group expired during study follow-up $(p$-Value $=0.245)$.

In patients with successful weaning, percentage of $\mathrm{pH}$ changes in the donepezil group was significant compared to the control group $(p$-Value $=0.048)$. Despite the upward trend in the profiles of the GCS over time in all three groups, no significant difference was observed between groups $(p$-Value $=0.084)($ Figure 2$)$. 
TABLE 1 | Characteristics of the patients at baseline.

\begin{tabular}{|c|c|c|c|c|}
\hline Parameters & Placebo ( $N=24)$ & $\begin{array}{l}\text { Medroxyprogesterone } \\
\qquad(\mathrm{N}=26)\end{array}$ & Donepezil ( $\mathbf{N}=23)$ & $p$-value \\
\hline Age, mean $\pm S D$ & $39.2 \pm 21$ & $45.5 \pm 20.8$ & $38.7 \pm 22.1$ & 0.483 \\
\hline Men, no. (\%) & $20(83.3)$ & $21(80.8)$ & $18(78.2)$ & 0.828 \\
\hline SOFA scores, mean \pm SD (points) & $7.6 \pm 1.7$ & $6.7 \pm 1.7$ & $7.1 \pm 2.1$ & 0.237 \\
\hline ICU stay before randomization, mean \pm SD $(h)$ & $54.0 \pm 58.8$ & $50.7 \pm 31.3$ & $45.9 \pm 27.9$ & 0.800 \\
\hline \multicolumn{5}{|l|}{ Coexisting conditions, no (\%) } \\
\hline Hypertension & $6(25)$ & $5(19.2)$ & $3(13)$ & 0.582 \\
\hline Diabetes mellitus & $0(0.0)$ & $0(0.0)$ & $1(4.34)$ & 0.332 \\
\hline Dyslipidemia & $0(0.0)$ & $1(3.8)$ & $0(0.0)$ & 0.400 \\
\hline Hyperactive delirium, no (\%) & $1(4.1)$ & $2(7.6)$ & $1(4.3)$ & 0.365 \\
\hline \multicolumn{5}{|l|}{ Causes of invasive mechanical ventilation, no. (\%) } \\
\hline Stroke & $9(37.5)$ & $17(65.3)$ & $12(52.1)$ & 0.147 \\
\hline Surgery & $4(16.6)$ & $2(7.6)$ & $4(17.3)$ & 0.550 \\
\hline Head trauma & $4(16.6)$ & $1(3.8)$ & $2(8.6)$ & 0.311 \\
\hline Brain edema & $2(8.3)$ & $1(3.8)$ & $3(13.0)$ & 0.515 \\
\hline Cerebral contusion & $2(8.3)$ & $1(3.8)$ & $1(4.3)$ & 0.761 \\
\hline Others & $3(12.5)$ & $4(15.3)$ & $1(4.3)$ & 0.379 \\
\hline \multicolumn{5}{|c|}{ Sedative, opioid and other CNS depressant medications, No. (\%) } \\
\hline Midazolam & $24(100)$ & $26(100)$ & $23(100)$ & 1.000 \\
\hline Fentanyl & $24(100)$ & $26(100)$ & $23(100)$ & 1.000 \\
\hline Morphine & $15(62.5)$ & $18(69.2)$ & $18(78.2)$ & 0.498 \\
\hline Methadone & $2(8.3)$ & $1(3.8)$ & $1(4.3)$ & 0.753 \\
\hline Propofol & $1(4.1)$ & $0(0.0)$ & $1(4.3)$ & 0.566 \\
\hline Thiopental & $1(4.1)$ & $1(3.8)$ & $0(0.0)$ & 0.622 \\
\hline \multicolumn{5}{|l|}{ Other medications, No. (\%) } \\
\hline \multicolumn{5}{|l|}{ Antibiotic } \\
\hline Carbapenem & 0 & $2(7.6)$ & $1(4.3)$ & 0.422 \\
\hline Cephalosporins & $16(66.6)$ & $21(80.7)$ & $14(60.8)$ & 0.413 \\
\hline Glycopeptide & $5(0)$ & $5(19.2)$ & $2(8.6)$ & 0.457 \\
\hline Aminoglycoside & $2(8.3)$ & $4(15.3)$ & 4 (17.3) & 0.676 \\
\hline Clindamycin & 60 & $4(15.3)$ & $3(13)$ & 0.443 \\
\hline Penicillins & $1(4.1)$ & $1(3.8)$ & 0 & 0.617 \\
\hline \multicolumn{5}{|l|}{ Cardiovascular } \\
\hline Antiplatelet & $2(8.3)$ & $3(11.5)$ & 0 & 0.276 \\
\hline Anticoagulant & $12(50)$ & $10(38.4)$ & $9(39.1)$ & 0.497 \\
\hline ACEI/ARB & $3(12.5)$ & $2(7.6)$ & $3(13)$ & 0.752 \\
\hline $\mathrm{CCB}$ & $1(4.1)$ & $3(11.5)$ & $1(4.3)$ & 0.547 \\
\hline B-Blockers & $5(20.8)$ & $6(23)$ & $3(13)$ & 0.666 \\
\hline Nitrate & 0 & $1(3.8)$ & 0 & 0.424 \\
\hline Diuretics & $6(25)$ & 7 (26.9) & $3(13)$ & 0.461 \\
\hline \multicolumn{5}{|l|}{ Anticonvulsant } \\
\hline Phenytoin & $7(29.1)$ & $5(19.2)$ & $6(26)$ & 0.598 \\
\hline Valproate sodium & $2(8.3)$ & $4(15.3)$ & $4(17.3)$ & 0.688 \\
\hline Gastrointestinal & & & & \\
\hline H2B/PPI & $20(83.3)$ & $25(96.1)$ & $18(78.2)$ & 0.253 \\
\hline Prokinetic agents & $5(20.8)$ & $8(30.7)$ & $4(17.3)$ & 0.586 \\
\hline \multicolumn{5}{|l|}{ Others } \\
\hline Corticosteroids & $8(33.3)$ & 7 (26.9) & $5(21.7)$ & 0.589 \\
\hline NSAIDs/Acetaminophen & $10(41.6)$ & 8 (30.7) & $5(21.7)$ & 0.274 \\
\hline Ascorbic acid & $7(29.1)$ & $9(34.6)$ & $10(43.4)$ & 0.687 \\
\hline Insulin & $2(8.3)$ & 0 & $1(4.3)$ & 0.300 \\
\hline \multicolumn{5}{|l|}{ Laboratory measurements at inclusion, Mean \pm SD } \\
\hline $\mathrm{pH}$ & $7.37 \pm 0.09$ & $7.37 \pm 0.84$ & $7.36 \pm 0.05$ & 0.789 \\
\hline $\mathrm{PaO}_{2}, \mathrm{~mm} \mathrm{Hg}$ & $130.0 \pm 48.7$ & $137.1 \pm 50.8$ & $131.0 \pm 52.4$ & 0.867 \\
\hline $\mathrm{PaCO}_{2}, \mathrm{~mm} \mathrm{Hg}$ & $38.9 \pm 8.8$ & $37.3 \pm 11.3$ & $40.4 \pm 7.1$ & 0.523 \\
\hline $\mathrm{HCO}_{3}, \mathrm{mEq} / \mathrm{L}$ & $22.8 \pm 4.4$ & $20.8 \pm 5.2$ & $21.8 \pm 3.6$ & 0.331 \\
\hline
\end{tabular}


TABLE 1 | (Continued) Characteristics of the patients at baseline.

\begin{tabular}{|c|c|c|c|c|}
\hline Parameters & Placebo $(\mathrm{N}=24)$ & $\begin{array}{l}\text { Medroxyprogesterone } \\
\qquad(\mathrm{N}=\mathbf{2 6})\end{array}$ & Donepezil ( $N=23$ ) & $p$-value \\
\hline Creatinine, mg/dL & $1.2 \pm 0.6$ & $1.3 \pm 1.0$ & $1.0 \pm 0.4$ & 0.402 \\
\hline Bilirubin, mg/dL & $0.8 \pm 0.3$ & $0.8 \pm 0.1$ & $0.7 \pm 0.4$ & 0.252 \\
\hline Hemoglobin, g/dL & $10.9 \pm 2.5$ & $11.2 \pm 2.0$ & $11.7 \pm 1.8$ & 0.608 \\
\hline Blood platelets, $\times 10^{3} / \mu \mathrm{L}$ & $140.6 \pm 59.4$ & $167.7 \pm 71.2$ & $144.8 \pm 49.0$ & 0.244 \\
\hline
\end{tabular}

No, Number; hrs, hours; SD, standard deviation; $\mathrm{pH}$, potential of hydrogen; $\mathrm{PaO}_{2}$, partial pressure of oxygen, arterial; $\mathrm{PaCO}_{2}$, partial pressure of carbon dioxide; mm Hg, millimeter of mercury; $\mathrm{HCO}_{3}$; Bicarbonate; $\mathrm{mEq} / \mathrm{L}$, mill equivalents per liter; $\mathrm{mg} / \mathrm{dL}$, milligrams per deciliter; $\mathrm{g} / \mathrm{dL}$, grams per deciliter; $\mu \mathrm{L}$, microliter; Chi-square were used to compare these values.

In non-successfully weaned patients, the total duration of ICU stay was on average 559.2 (276) and 758.4 (278) hrs in the medroxyprogesterone and donepezil groups in comparison to 532.8 (232.8) hrs in the control group, for a betweengroup difference of $-24.0 \mathrm{~h}$ and $-223.2 \mathrm{~h}$, respectively. This value did not change significantly in the groups ( $p$-value $=0.453$ ). The rate of ICU mortality in non-successfully weaned patients was $2(25 \%)$ in control, and no patient in other groups $(p$-Value $=0.480)$.

Moreover, the comparison other secondary endpoints, including arterial blood gas (ABG) parameters, O2Sat, Hgb, and SOFA score was done using the general linear model test. The results did not differ significantly after $24 \mathrm{~h}$ in nonsuccessfully and overtime in successfully weaned patients. There were no significant differences in mean difference of variables between each group compared to the others (Tables 3 and 4$)$.

\section{DISCUSSION}

Although, the effects of hormones such as progesterone on respiratory and ventilatory performance have been evaluated in previous studies, the present study is the first randomized, controlled clinical trial evaluating the effectiveness of medroxyprogesterone in facilitation of weaning in patients receiving invasive mechanical ventilation. The effect of donepezil was previously assessed in a clinical study to facilitate the weaning course. However, in this nonrandomized study, there was no control group and the effect of donepezil on ABG was evaluated in only 16 difficult to wean patients. According to the design of this aforementioned study, it had all the limitations of non-clinical trial studies. Therefore, this study is also the first randomized clinical trial of donepezil in expedition the weaning course in mechanically ventilated patients.

This triple-blind randomized clinical trial designed to compare the improvement in respiratory status and weaning facilitation in mechanical ventilated critically ill adult patients receiving donepezil or medroxyprogesterone vs. placebo. The mean total duration of invasive ventilation was significantly lower in the donepezil compared to the control group while the duration of weaning did differ significantly between the groups. In addition, the rate of successful weaning were greater in the donepezil and medroxyprogesterone groups compared to the control group, this difference was not statistically significant. Donepezil and medroxyprogesterone had no significant effect on the total duration of ICU stay, rate of ICU mortality, and GCS in successfully weaned patients which was not too far from expected, since there are several factors in the ICU setting influencing these parameters and it is not possible to control for all these confounders. In fact, parameters such as age, chronic use of corticosteroid, atrophy of diaphragmatic, or severe limitation of airway flow are far more vigorous factors affecting the successful rate of weaning from mechanical ventilation or outcomes of critically ill patients (Groenewegen et al., 2003; Boles et al., 2007; Levine et al., 2008). Taken together, although patients in donepezil and medroxyprogesterone groups were more successful than the control group in the weaning process, this difference was not statistically significant.

Mechanical ventilation is implemented to improve oxygen delivery and ventilation, and decrease the breathing workload. It is by the physician to and is therefore a means of treating the patient. Physicians adopt MV to stabilize the patient until the diagnosis and therapeutic management of the disease is performed (Boles et al., 2007). In other words, MV is a means to an end and not a treatment in itself. Therefore, the weaning

TABLE 2 | Trends of changes in primary outcomes.

\begin{tabular}{|c|c|c|c|c|}
\hline \multirow{2}{*}{$\begin{array}{l}\text { Variables } \\
\text { Duration of invasive mechanical ventilation, hours }\end{array}$} & \multicolumn{2}{|c|}{ Comparing } & \multirow{2}{*}{$\begin{array}{l}\text { Between-group mean difference } \\
\qquad+33.600\end{array}$} & \multirow{2}{*}{$\begin{array}{c}\boldsymbol{p} \text {-value } \\
0.161\end{array}$} \\
\hline & placebo & Medroxyprogesterone & & \\
\hline & & donepezil & +51.768 & $0.020^{a}$ \\
\hline & Medroxyprogesterone & donepezil & +18.144 & 0.511 \\
\hline \multirow[t]{3}{*}{ Weaning duration, hours } & placebo & Medroxyprogesterone & +34.296 & $0.038^{a}$ \\
\hline & & donepezil & +42.600 & $0.010^{a}$ \\
\hline & Medroxyprogesterone & donepezil & +8.280 & 0.793 \\
\hline
\end{tabular}

${ }^{a}$ Statistically significant ( $\mathrm{p}$-Value $\left.<0.05\right)$. ANOVA and Tukey HSD, tests were used to compare these values. 


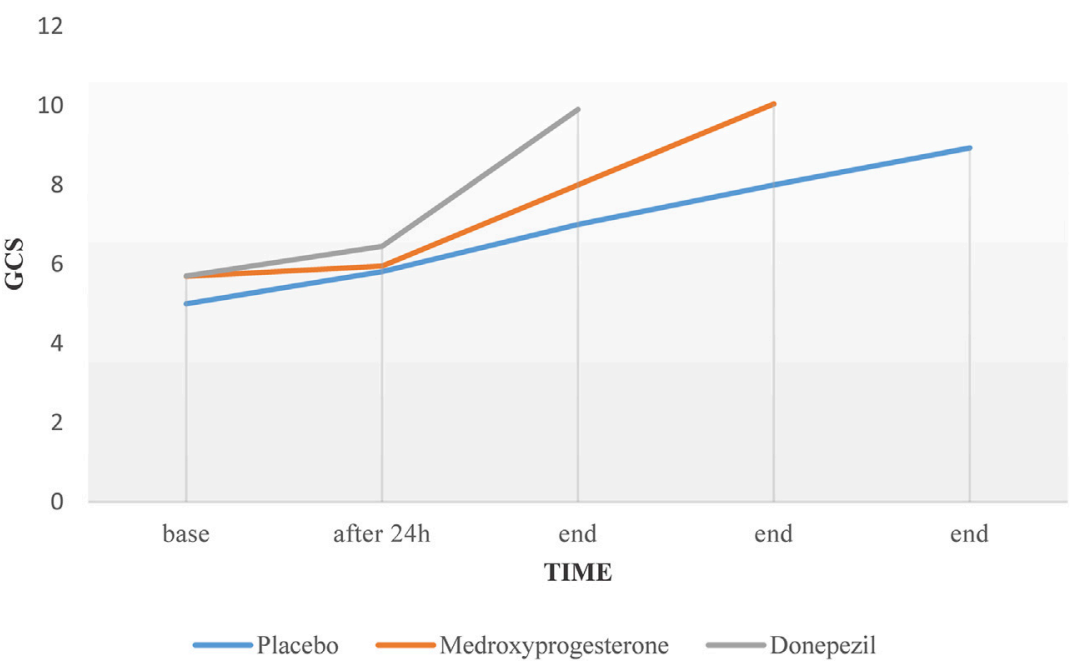

FIGURE 2 | Mean variations of GCS in three different groups over the time.

process should be initiated as soon as possible (McLean et al., 2006).

Despite the salvage of MV in critically ill patients, MV is associated with numerous complications. The most common complications are pneumothorax, broncho pleural fistula, nosocomial pneumonia, and respiratory alkalosis, which can impair cerebral perfusion, predispose patients to cardiac dysrhythmias, and prolong the weaning process (Groenewegen et al., 2003). Difficulty in weaning can be due to reduced central respiratory stimulants that suggesting new strategies to reduce the duration of intubation and treatment costs.

Some other agents such as methylphenidate, benzquinamide, ethamivan, bemegride, nikethamide, naloxone, almitrin, theophylline, methyl xanthine, levosimendan, and acetazolamide have been tried as the respiratory stimulants (Dallemagne and Heymans, 1955; Yost, 2006; Roesthuis et al., 2019), but the results of these studies were not encouraging.

The efficacy of acetazolamide in the duration of intubation was evaluated as regards the results did not show reduction in intubation and weaning process (Faisy et al., 2016).

Donepezil and medroxyprogesterone at dose of $10 \mathrm{mg}$ are well tolerated without causing any life-threatening side effect (Soufir et al., 2011; Tan et al., 2014). Mechanically ventilated patients with potential difficulties in respiratory drive were enrolled. Due to the stimulatory properties of progesterone in the central respiratory system and the role of the cholinergic system in

TABLE 3 | Secondary outcomes in successfully weaned patients before, after $24 \mathrm{~h}$, and when weaning happened.

\begin{tabular}{|c|c|c|c|c|c|c|c|c|c|c|}
\hline \multirow[t]{2}{*}{ Variables } & \multicolumn{9}{|c|}{ Group, mean \pm SD } & \multirow[t]{2}{*}{$p$-value } \\
\hline & \multicolumn{3}{|c|}{ Placebo $(N=16)$} & \multicolumn{3}{|c|}{ Medroxyprogesterone ( $\mathbf{N}=\mathbf{2 3}$ ) } & \multicolumn{3}{|c|}{ Donepezil (N = 20) } & \\
\hline $\begin{array}{l}\text { Successful weaning, } \\
\text { No. (\%) }\end{array}$ & \multicolumn{3}{|c|}{16 of $24(66.7)$} & \multicolumn{3}{|c|}{23 of 26 (88.5) } & \multicolumn{3}{|c|}{20 of $23(87)$} & 0.111 \\
\hline ICU stay, hrs & \multicolumn{3}{|c|}{$434.4 \pm 170.4$} & \multicolumn{3}{|c|}{$453.6 \pm 232.8$} & \multicolumn{3}{|c|}{$352.8 \pm 180$} & 0.245 \\
\hline \multirow[t]{2}{*}{ ICU mortality, No. (\%) } & \multicolumn{3}{|c|}{$4(25)$} & \multicolumn{3}{|c|}{$5(21.7)$} & \multicolumn{3}{|c|}{$3(15)$} & 0.753 \\
\hline & before & $24 \mathrm{~h}$ & AW & before & $24 \mathrm{~h}$ & AW & before & $24 \mathrm{~h}$ & AW & \\
\hline \multicolumn{11}{|l|}{ ABG parameters } \\
\hline $\mathrm{O}_{2}$ Sat, $\%$ & $96.5 \pm 1.9$ & $97.5 \pm 1.5$ & $97.5 \pm 1.8$ & $97.2 \pm 1.4$ & $96.9 \pm 3.5$ & $97.2 \pm 1.7$ & $97.4 \pm 2.1$ & $97.8 \pm 1.2$ & $96.8 \pm 1.9$ & 0.726 \\
\hline $\mathrm{PaO}_{2}, \mathrm{~mm} \mathrm{Hg}$ & $\begin{array}{c}129.4 \pm \\
36.9\end{array}$ & $\begin{array}{c}114.5 \pm \\
15.5\end{array}$ & $\begin{array}{c}118.9 \pm \\
33.9\end{array}$ & $\begin{array}{c}134.4 \pm \\
52.3\end{array}$ & $\begin{array}{c}130.7 \pm \\
39.5\end{array}$ & $\begin{array}{c}113.3 \pm \\
16.6\end{array}$ & $\begin{array}{c}132.2 \pm \\
55.5\end{array}$ & $\begin{array}{c}121.5 \pm \\
31.6\end{array}$ & $\begin{array}{c}106.3 \pm \\
29.0\end{array}$ & 0.655 \\
\hline $\mathrm{PaCO}_{2}, \mathrm{~mm} \mathrm{Hg}$ & $38.6 \pm 10.0$ & $35.4 \pm 12.3$ & $36.0 \pm 6.1$ & $36.9 \pm 12.0$ & $35.7 \pm 12.3$ & $35.4 \pm 5.7$ & $40.4 \pm 7.6$ & $36.0 \pm 8.3$ & $35.2 \pm 4.8$ & 0.460 \\
\hline $\mathrm{HCO}_{3}, \mathrm{mEq} / \mathrm{L}$ & $22.1 \pm 3.6$ & $5.2 \pm 21.9$ & $23.2 \pm 3.7$ & $20.6 \pm 5.4$ & $22.6 \pm 4.8$ & $24.1 \pm 3.0$ & $26.0 \pm 4.5$ & $22.2 \pm 3.8$ & $23.2 \pm 4.0$ & 0.655 \\
\hline $\mathrm{pH}$ & $7.37 \pm 0.10$ & $7.41 \pm 0.07$ & $7.42 \pm 0.08$ & $7.37 \pm 0.08$ & $7.39 \pm 0.11$ & $7.40 \pm 0.05$ & $7.36 \pm 0.05$ & $7.39 \pm 0.05$ & $7.41 \pm 0.05$ & $0.048^{a}$ \\
\hline Hemoglobin, g/dl & $10.9 \pm 2.5$ & $10.7 \pm 2.4$ & $10.3 \pm 1.8$ & $11.2 \pm 2.0$ & $10.7 \pm 1.9$ & $10.5 \pm 2.3$ & $11.7 \pm 1.8$ & $11.1 \pm 2.0$ & $11.1 \pm 1.8$ & 0.143 \\
\hline GCS & $5.0 \pm 0.9$ & $5.8 \pm 1.1$ & $8.9 \pm 0.7$ & $5.6 \pm 1.2$ & $5.9 \pm 1.6$ & $10.0 \pm 1.1$ & $5.7 \pm 1.2$ & $6.4 \pm 1.7$ & $9.9 \pm 1.2$ & 0.084 \\
\hline SOFA scores, points & $7.9 \pm 1.8$ & $7.1 \pm 1.7$ & $3.8 \pm 1.2$ & $6.7 \pm 1.8$ & $8.1 \pm 1.9$ & $3.2 \pm 1.0$ & $6.9 \pm 2.1$ & $8.1 \pm 1.6$ & $3.3 \pm 1.2$ & 0.655 \\
\hline
\end{tabular}

No, number; $\mathrm{SD}$, standard deviation; $\mathrm{ABG}$, arterial blood gas; $\mathrm{pH}$, potential of Hydrogen; $\mathrm{PaO}_{2}$, partial pressure of oxygen; $\mathrm{PaCO}$, partial pressure of carbon dioxide; $m$ m $\mathrm{Hg}$, millimeter of mercury; $\mathrm{HCO}_{3}$; Bicarbonate; $\mathrm{mEq} / \mathrm{L}$, mill equivalents per liter; mg/dl, milligrams per deciliter; g/dl, grams per deciliter; GCS, glasgow coma scale; SOFA, sequential organ failure assessment score; AW, after weaning.

${ }^{a}$ Statistically significant ( $\mathrm{p}$-Value $\left.<0.05\right)$ 
the neurological control of respiration, this study was performed. Administration of oral medroxyprogesterone or donepezil in the clinical setting for weaning from MV is limited. No adverse effects were seen in either group.

Medroxyprogesterone could reduce the duration of intubation significantly. We monitored respiratory ventilation function by obtaining serial ABG samples. However, no significant difference observed in all variables of ABG after $24 \mathrm{~h}$ and after successful weaning in the medroxyprogesterone group compared with the control group. Contrary to the results of the present study, two previous studies that were conducted on patients with chronic obstructive pulmonary disease (COPD) illustrated the effective role of medroxyprogesterone in $\mathrm{PaCO}_{2}$ reduction and $\mathrm{PO}_{2}$ increment (Delaunois et al., 1985; Wagenaar et al., 2003). It should be borne in mind that the dosing of medroxyprogesterone was lower in the current study.

In an interventional pilot study, the effect of donepezil on the facilitation of weaning in difficult to wean patients was evaluated. Donepezil was administered for eligible patients at the dose of $10 \mathrm{mg}$ daily for 2-4 weeks. It was presumed that donepezil could expedite weaning by stimulation of respiratory center and prevent the need for re-intubation in these patients. However, they included a small number of patients (16 patients) as well as non-randomization limited the establishment of a strong relationship between use of donepezil and facilitation of weaning (Abbasi et al., 2015). Our results showed that donepezil was able to facilitate the patient's weaning but did not alter $\mathrm{PaO}_{2}, \mathrm{PaCO}_{2}, \mathrm{HCO}_{3}$ concentration, and $\mathrm{O}_{2}$ Sat parameters while contrary to Abbasi's study $\mathrm{pH}$ changes were significant in this study. Although no significant different in $\mathrm{pH}$ changes were seen in the donepezil compared to control group after $24 \mathrm{~h}$, changes in $\mathrm{pH}$ were significant overtime indicating that several doses of the donepezil are required for an efficient response. It can be argued that the results of ABG parameters such as $\mathrm{pH}$ will often influence the weaning process accompanied with better clinical outcome in such patients (Kraut and Madias, 2012).
We also evaluated the effect of donepezil and medroxyprogesterone on the improvement of the patient's GCS. In the clinical setting, the improvement in GCS is one of the important criteria for initiation of weaning. In other words, low GCS at the beginning of the weaning process is considered a major reason for prolongation of this process (Pu et al., 2015). In this study, despite the increase in GCS over time, this difference was not statistically significant when compared to control group. but this issue, especially in the case of donepezil, requires study in larger populations and longer time because the cholinergic system is one of the most important cognitive centers in the brain (Zhang et al., 2004).

SOFA is a valuable score for the management of patients in ICUs which predicts patients' outcomes (Ferreira et al., 2001). GCS and $\mathrm{PaO}_{2}$ are two main indices for calculation of SOFA score. Due to the lack of changes in GCS and $\mathrm{PaO}_{2}$ in both groups compared to placebo, changes in this index were not significant between intervention and placebo groups, so these two drugs are not effective in reducing the SOFA score and mortality rate.

Duration of weaning was significantly reduced in intervention groups compared to the control group. The underlying mechanisms for donepezil are presumed to be due to the performance of the cholinergic system in improving respiratory coordination, increased neuromuscular transmission, improved upper respiratory muscle function, neuronal control of respiration, and increased salivary secretion (Hedner et al., 2003; Proctor and Carpenter, 2014). The performance of medroxyprogesterone in strengthening the tidal volume (VT), respiratory effort, changes in metabolic rate, lung and chest movements, increase ventilation performance and increasing ventilation capacity (Golparvar et al., 2005; Dempsey et al., 2011).

This study has several limitations. First, the main limitation was the small size of the subject groups. Despite more than 7 month study duration and inclusion of consecutive patients, only limited number of patients entered the study according to inclusion and exclusion criteria. Second, while the dose range

TABLE 4 | Secondary outcomes in non-successfully weaned patients before and after $24 \mathrm{~h}$.

Variables

Group, mean \pm SD

p-value

\begin{tabular}{|c|c|c|c|c|c|c|c|}
\hline & \multirow{2}{*}{\multicolumn{2}{|c|}{ Placebo $(\mathrm{N}=8)$}} & \multirow{2}{*}{\multicolumn{2}{|c|}{ Medroxyprogesterone $(\mathrm{N}=3$ ) }} & \multirow{2}{*}{\multicolumn{2}{|c|}{ Donepezil (N = 3) }} & \\
\hline & & & & & & & \\
\hline ICU stay, hrs & \multicolumn{2}{|c|}{$532.8 \pm 218.4$} & \multicolumn{2}{|c|}{$559.2 \pm 276$} & \multicolumn{2}{|c|}{$758.4 \pm 276$} & 0.430 \\
\hline \multirow[t]{2}{*}{ ICU mortality, No. (\%) } & \multicolumn{2}{|c|}{$2(25)$} & \multicolumn{2}{|c|}{0} & \multicolumn{2}{|c|}{0} & 0.480 \\
\hline & before & $24 \mathrm{~h}$ & before & $24 \mathrm{~h}$ & before & $24 \mathrm{~h}$ & \\
\hline \multicolumn{8}{|l|}{ ABG parameters } \\
\hline $\mathrm{O}_{2}$ Sat, \% & $94.8 \pm 6.8$ & $98.1 \pm 0.9$ & $97.3 \pm 2$ & $98 \pm 0$ & $96 \pm 1$ & $96.6 \pm 1.5$ & 0.220 \\
\hline $\mathrm{PaO}_{2}, \mathrm{~mm} \mathrm{Hg}$ & $131.3 \pm 69.7$ & $124.7 \pm 37.6$ & $157.6 \pm 37.2$ & $130.6 \pm 30$ & $123 \pm 29.5$ & $114 \pm 27.4$ & 0.930 \\
\hline $\mathrm{PaCO}_{2}, \mathrm{~mm} \mathrm{Hg}$ & $39.3 \pm 6.4$ & $37.3 \pm 6.2$ & $40.3 \pm 3$ & $30.6 \pm 6.1$ & $40.6 \pm 1.5$ & $39.3 \pm 6.8$ & 0.719 \\
\hline $\mathrm{HCO}_{3}, \mathrm{mEq} / \mathrm{L}$ & $24.1 \pm 5.8$ & $24 \pm 3.2$ & $22.8 \pm 3.2$ & $21 \pm 5.3$ & $22.4 \pm 2.9$ & $24.4 \pm 2.1$ & 0.367 \\
\hline $\mathrm{pH}$ & $7.38 \pm 0.77$ & $7.38 \pm 0.67$ & $7.37 \pm 0.72$ & $7.45 \pm 0.06$ & $7.35 \pm 0.37$ & $7.42 \pm 0.02$ & 0.941 \\
\hline Hemoglobin, g/dl & $11.1 \pm 2.7$ & $10.3 \pm 2.4$ & $12.1 \pm 1.4$ & $11.7 \pm 0.6$ & $11.5 \pm 1.2$ & $11.5 \pm 0.8$ & 0.540 \\
\hline GCS & $5.5 \pm 1.1$ & $5.2 \pm 0.7$ & $4.6 \pm 0.5$ & $5 \pm 0$ & $4.6 \pm 1.1$ & $4.6 \pm 0.57$ & 0.569 \\
\hline SOFA scores, points & $7 \pm 1.3$ & $8.1 \pm 2.4$ & $6.3 \pm 0.5$ & $8.3 \pm 2$ & $8.6 \pm 1.5$ & $8 \pm 1.7$ & 0.199 \\
\hline
\end{tabular}

No, number; $\mathrm{SD}$, standard deviation; $\mathrm{ABG}$, arterial blood gas; $\mathrm{pH}$, potential of Hydrogen; $\mathrm{PaO}_{2}$, partial pressure of oxygen; $\mathrm{PaCO}$, partial pressure of carbon dioxide; $m$ m $\mathrm{Hg}$, millimeter of mercury; $\mathrm{HCO}_{3}$; Bicarbonate; $\mathrm{mEq} / \mathrm{L}$, mill equivalents per liter; $\mathrm{mg} / \mathrm{dl}$, milligrams per deciliter; g/dL, grams per deciliter; GCS, glasgow coma scale; SOFA, sequential organ failure assessment score. 
of medroxyprogesterone was different in previous data, the effective dose for weaning from MV is yet to be determined. Although the interventions performed in this study were safe and no side effects related to these drugs were reported during the study period, but considering the relative short length of the intervention and follow-up period, the necessary precautions should be taken in this regard. Furthermore, the lack of a fixed and predefined protocol for all patients for whom weaning is to be attempted is another limitation which should be taken into consideration in future studies. The last limitation is the presence of factors more strongly influencing the discontinuation of MV or ICU outcomes (eg, age, diagnosis, long-term use of steroids or diaphragm atrophy).

Various population pharmacokinetic parameters and contribution of different factors in weaning process might be the reasons for medroxyprogesterone or donepezil treatment to achieve its response goal during the studies. Therefore, these results require further confirmation with larger controlled clinical trials to clarify and establish medroxyprogesterone and donepezil role on weaning process. Moreover, other confounding factors that strongly influencing the patients' outcome should be considered.

\section{CONCLUSION}

Previous investigation found that some respiratory stimulants could facilitate weaning presses. Medroxyprogesterone and donepezil are two safe and successful respiratory stimulants, suggesting that they could be considered as a weaning-facilitating strategy. Our results illustrated that the administered dose of medroxyprogesterone and donepezil can expedite the weaning process presumably by central stimulation of the respiratory system.

The results of the current study have demonstrated that administering medroxyprogesterone or donepezil in the weaning process significantly reduced the weaning duration compared to placebo, while the total duration of invasive ventilation was significantly lower in the donepezil group compared to the control group. There were no statistically significant differences in other evaluated outcomes except $\mathrm{pH}$ changes. Although the findings of the present study are interesting, care should be taken in implementing these results.

\section{REFERENCES}

Abbasi, S., Farsaei, S., Fazel, K., Golzari, S. E., and Mahmoodpoor, A. (2015). Can Donepezil Facilitate Weaning from Mechanical Ventilation in Difficult to Wean Patients? an Interventional Pilot Study. Daru 23 (1), 23. doi:10.1186/s40199-0150103-z

Bayliss, D. A., and Millhorn, D. E. (1992). Central Neural Mechanisms of Progesterone Action: Application to the Respiratory System. J. Appl. Physiol. (1985) 73 (2), 393-404. doi:10.1152/jappl.1992.73.2.393

Boles, J. M., Bion, J., Connors, A., Herridge, M., Marsh, B., Melot, C., et al. (2007). Weaning from Mechanical Ventilation. Eur. Respir. J. 29 (5), 1033-1056. doi:10.1183/09031936.00010206

Chao, D. C., and Scheinhorn, D. J. (1998). Weaning from Mechanical Ventilation. Crit. Care Clin. 14 (4), 799-viii. doi:10.1016/s0749-0704(05)70031-2

\section{DATA AVAILABILITY STATEMENT}

The raw data supporting the conclusions of this article will be made available by the authors, without undue reservation.

\section{ETHICS STATEMENT}

The studies involving human participants were reviewed and approved by Ethics ID (IR.SSU.MEDICINE.REC.1398.198) by the Ethics Committee of Shahid Sadoughi University of Medical Sciences. The patients/participants provided their written informed consent to participate in this study.

\section{AUTHOR CONTRIBUTIONS}

FS and AS were involved in the conception and design of the study. ZA and NH collected the data. ZA and FM prepared the placebo tablets. FM packed the placebo, medroxyprogesterone, and donepezil tablets in the same packages. FS and ZA analyzed the data and drafted the first manuscript. All authors read and approved the final manuscript.

\section{FUNDING}

The manuscript was financially supported by a grant from the Research and Technology Department of Shahid Sadoughi University of Medical Sciences (grant no. 6855), Yazd, Iran.

\section{ACKNOWLEDGMENTS}

This article is derived from the thesis "Evaluation of effects of oral medroxyprogesterone and donepezil in improvement of respiratory status and facilitation in weaning of mechanical ventilation in patients undergoing mechanical ventilation in ICUs of Shahid Rahnemoon Yazd" supervised by Assistant Professor FS and submitted by FS to the Faculty of Pharmacy of Shahid Sadoughi University of Medical Sciences, Yazd, Iran, in partial fulfillment of the requirements for the Degree of Pharm-D of ZA.

Cohen, J. N., Gopal, A., Roberts, K. J., Anderson, E., and Siegel, A. M. (2019). VentilatorDependent Patients Successfully Weaned with Cognitive-Behavioral Therapy: A Case Series. Psychosomatics 60 (6), 612-619. doi:10.1016/j.psym.2019.02.003

Dallemagne, M. J., and Heymans, C. (1955). Chapter 40 Respiratory Stimulants. Alkaloids: Chem. Physiol. 5, 109-139. Elsevier. doi:10.1016/s1876-0813(08)60083-4

Dasta, J. F., McLaughlin, T. P., Mody, S. H., and Piech, C. T. (2005). Daily Cost of an Intensive Care Unit Day: the Contribution of Mechanical Ventilation. Crit. Care Med. 33 (6), 1266-1271. doi:10.1097/01.ccm.0000164543.14619.00

Delaunois, L., Delwiche, J. P., and Lulling, J. (1985). Effect of Medroxyprogesterone on Ventilatory Control and Pulmonary Gas Exchange in Chronic Obstructive Patients. Respiration 47 (2), 107-113. doi:10.1159/000194756

Dempsey, J. A., Olson, E. B., Jr, and Skatrud, J. B. (2011). Hormones and Neurochemicals in the Regulation of Breathing. Compr. Physiol. 1, 181-221. doi:10.1002/cphy.cp030207

Dries, D. J., and Perry, J. F. (2008). Mechanical Ventilation. Surgery, 577-595. doi:10.1007/978-0-387-68113-9_32 
Faisy, C., Meziani, F., Planquette, B., Clavel, M., Gacouin, A., Bornstain, C., et al. (2016). Effect of Acetazolamide vs Placebo on Duration of Invasive Mechanical Ventilation Among Patients with Chronic Obstructive Pulmonary Disease: a Randomized Clinical Trial. Jama 315 (5), 480-488. doi:10.1001/jama.2016.0019

Ferreira, F. L., Bota, D. P., Bross, A., Mélot, C., and Vincent, J. L. (2001). Serial Evaluation of the SOFA Score to Predict Outcome in Critically Ill Patients. Jama 286 (14), 1754-1758. doi:10.1001/jama.286.14.1754

Giguère, S., Slade, J. K., and Sanchez, L. C. (2008). Retrospective Comparison of Caffeine and Doxapram for the Treatment of Hypercapnia in Foals with Hypoxic-Ischemic Encephalopathy. J. Vet. Intern. Med. 22 (2), 401-405. doi:10.1111/j.19391676.2008.0064.x

Gilman, S., Chervin, R. D., Koeppe, R. A., Consens, F. B., Little, R., An, H., et al. (2003). Obstructive Sleep Apnea Is Related to a Thalamic Cholinergic Deficit in MSA. Neurology 61 (1), 35-39. doi:10.1212/01.wnl.0000073624.13436.32

Golparvar, M., Ahmadi, F., and Saghaei, M. (2005). Effects of Progesterone on the Ventilatory Performance in Adult Trauma Patients during Partial Support Mechanical Ventilation. Arch. iranian Med. 8, 27-31.

Groenewegen, K. H., Schols, A. M., and Wouters, E. F. (2003). Mortality and Mortality-Related Factors after Hospitalization for Acute Exacerbation of COPD. Chest 124 (2), 459-467. doi:10.1378/chest.124.2.459

Hedner, J., Kraiczi, H., Peker, Y., and Murphy, P. (2003). Reduction of SleepDisordered Breathing after Physostigmine. Am. J. Respir. Crit. Care Med. 168 (10), 1246-1251. doi:10.1164/rccm.200211-1344OC

Heunks, L. M., and Van Der Hoeven, J. G. (2010). Clinical Review: the ABC of Weaning Failure-Aa Structured Approach. Crit. Care 14 (6), 245-249. doi:10.1186/cc9296

Kraut, J. A., and Madias, N. E. (2012). Treatment of Acute Metabolic Acidosis: a Pathophysiologic Approach. Nat. Rev. Nephrol. 8 (10), 589-601. doi:10.1038/ nrneph.2012.186

Levine, S., Nguyen, T., Taylor, N., Friscia, M. E., Budak, M. T., Rothenberg, P., et al. (2008). Rapid Disuse Atrophy of Diaphragm Fibers in Mechanically Ventilated Humans. N. Engl. J. Med. 358 (13), 1327-1335. doi:10.1056/NEJMoa070447

McLean, S. E., Jensen, L. A., Schroeder, D. G., Gibney, N. R., and Skjodt, N. M. (2006). Improving Adherence to a Mechanical Ventilation Weaning Protocol for Critically Ill Adults: Outcomes after an Implementation Program. Am. J. Crit. Care 15 (3), 299-309. doi:10.4037/ajcc2006.15.3.299

Moraes, W., Poyares, D., Sukys-Claudino, L., Guilleminault, C., and Tufik, S. (2008). Donepezil Improves Obstructive Sleep Apnea in Alzheimer Disease: a Double-Blind, Placebo-Controlled Study. Chest 133 (3), 677-683. doi:10.1378/chest.07-1446

Peñuelas, O., Frutos-Vivar, F., Fernández, C., Anzueto, A., Epstein, S. K., Apezteguía, C., et al. (2011). Characteristics and Outcomes of Ventilated Patients According to Time to Liberation from Mechanical Ventilation. Am. J. Respir. Crit. Care Med. 184 (4), 430-437. doi:10.1164/rccm.201011-1887oc

Pisanski, A., and Pagliardini, S. (2019). The Parafacial Respiratory Group and the Control of Active Expiration. Respir. Physiol. Neurobiol. 265, 153-160. doi:10.1016/ j.resp.2018.06.010

Proctor, G. B., and Carpenter, G. H. (2014). Salivary Secretion: Mechanism and Neural Regulation. Saliva: Secretion and Functions 24, 14-29. doi:10.1159/000358781

Pu, L., Zhu, B., Jiang, L., Du, B., Zhu, X., Li, A., et al. (2015). Weaning Critically Ill Patients from Mechanical Ventilation: a Prospective Cohort Study. J. Crit. Care 30 (4), 862.e7-13. doi:10.1016/j.jcrc.2015.04.001

Roesthuis, L., van der Hoeven, H., Sinderby, C., Frenzel, T., Ottenheijm, C., Brochard, L., et al. (2019). Effects of Levosimendan on Respiratory Muscle Function in Patients Weaning from Mechanical Ventilation. Intensive Care Med. 45 (10), 1372-1381. doi:10.1007/s00134-019-05767-y
Saaresranta, T., Aittokallio, T., Utriainen, K., and Polo, O. (2005). Medroxyprogesterone Improves Nocturnal Breathing in Postmenopausal Women with Chronic Obstructive Pulmonary Disease. Respir. Res. 6 (1), 28-12. doi:10.1186/1465-9921-6-28

Saaresranta, T., Irjala, K., and Polo, O. (2002). Effect of Medroxyprogesterone on Arterial Blood Gases, Leptin and Neuropeptide Y in Postmenopausal Females. Eur. Respir. J. 20 (6), 1413-1418. doi:10.1183/09031936.02.00281902

Schoene, R. B., Pierson, D. J., Lakshminarayan, S., Shrader, D. L., and Butler, J. (1980). Effect of Medroxyprogesterone Acetate on Respiratory Drives and Occlusion Pressure. Bull. Eur. Physiopathol Respir. 16 (5), 645-653.

Soufir, J. C., Meduri, G., and Ziyyat, A. (2011). Spermatogenetic Inhibition in Men Taking a Combination of Oral Medroxyprogesterone Acetate and Percutaneous Testosterone as a Male Contraceptive Method. Hum. Reprod. 26 (7), 1708-1714. doi:10.1093/ humrep/der138

Sukys-Claudino, L., Moraes, W., Guilleminault, C., Tufik, S., and Poyares, D. (2012). Beneficial Effect of Donepezil on Obstructive Sleep Apnea: a DoubleBlind, Placebo-Controlled Clinical Trial. Sleep Med. 13 (3), 290-296. doi:10.1016/j.sleep.2011.09.014

Tan, C. C., Yu, J. T., Wang, H. F., Tan, M. S., Meng, X. F., Wang, C., et al. (2014). Efficacy and Safety of Donepezil, Galantamine, Rivastigmine, and Memantine for the Treatment of Alzheimer's Disease: a Systematic Review and MetaAnalysis. J. Alzheimers Dis. 41 (2), 615-631. doi:10.3233/JAD-132690

Wagenaar, M., Vos, P., Heijdra, Y., Teppema, L., and Folgering, H. (2003). Comparison of Acetazolamide and Medroxyprogesterone as Respiratory Stimulants in Hypercapnic Patients with COPD. Chest 123 (5), 1450-1459. doi:10.1378/chest.123.5.1450

Yamada, M., and Ichinose, M. (2018). The Cholinergic Anti-inflammatory Pathway: an Innovative Treatment Strategy for Respiratory Diseases and Their Comorbidities. Curr. Opin. Pharmacol. 40, 18-25. doi:10.1016/j.coph.2017.12.003

Yost, C. S. (2006). A New Look at the Respiratory Stimulant Doxapram. CNS Drug Rev. 12 (3-4), 236-249. doi:10.1111/j.1527-3458.2006.00236.x

Zein, H., Baratloo, A., Negida, A., and Safari, S. (2016). Ventilator Weaning and Spontaneous Breathing Trials; an Educational Review. Emerg (Tehran) 4 (2), 65-71.

Zhang, L., Plotkin, R. C., Wang, G., Sandel, M. E., and Lee, S. (2004). Cholinergic Augmentation with Donepezil Enhances Recovery in Short-Term Memory and Sustained Attention after Traumatic Brain Injury. Arch. Phys. Med. Rehabil. 85 (7), 1050-1055. doi:10.1016/j.apmr.2003.10.014

Conflict of Interest: The authors declare that the research was conducted in the absence of any commercial or financial relationships that could be construed as a potential conflict of interest.

Publisher's Note: All claims expressed in this article are solely those of the authors and do not necessarily represent those of their affiliated organizations, or those of the publisher, the editors and the reviewers. Any product that may be evaluated in this article, or claim that may be made by its manufacturer, is not guaranteed or endorsed by the publisher.

Copyright (c) 2021 Alizadeh, Sahebnasagh, Hadadzadegan, Mohammadi and Saghafi. This is an open-access article distributed under the terms of the Creative Commons Attribution License (CC BY). The use, distribution or reproduction in other forums is permitted, provided the original author(s) and the copyright owner(s) are credited and that the original publication in this journal is cited, in accordance with accepted academic practice. No use, distribution or reproduction is permitted which does not comply with these terms. 


\section{GLOSSARY}

ANOVA Analysis of variance

ABG arterial blood gas

BUN blood urea nitrogen

$\mathbf{c m ~} \mathbf{H}_{2} \mathrm{O}$ centimeters of water

C centigrade degrees

CI Confidence Interval

COPD chronic obstructive pulmonary disease.

CNS central nervous system

$\mathrm{FIO}_{2}$ Fraction of inspired oxygen

GCS glasgow coma scale

hr hours

mg milligram

Hbg hemoglobin

ICU intensive care unit

MV Mechanical Ventilation

$\mathbf{O}_{2}$ Sat oxygen saturation
OSA obstructive sleep apnea

pH potential of hydrogen

SOFA sequential organ failure assessment

PEEP positive end-expiratory pressure

mmol/L mill moles per liter

$\mathbf{m E q} / \mathbf{L}$ mill equivalents per liter

$\mathbf{m l} / \mathbf{m i n}$ mill per minute

BID twice a day

$\mathrm{PaO}_{2}$ partial pressure of oxygen

$\mathrm{PaCO}_{2}$ partial pressure of carbon dioxide

HCO3 Bicarbonate

mm Hgmillimeter of mercury mg/dL millimeter of mercury mg/ dLmilligrams per deciliter

g/dL grams per deciliter

SPSS Statistical package for social science

MD mean difference

IQR Inter Quartile Range 